\title{
Effects of Environmental Factors on Fingerprint Development
}

\author{
Yakup Gulekci ${ }^{1 * *}$ \\ $1^{*}$ Kütahya University of Health Science, Faculty of Engineering and Natural Sciences, Forensic Sciences Department, Kütahya, Turkey, (ORCID: 0000-0001-9643- \\ 6850),yakup.gulekci@ksbu.edu.tr
}

(International Conference on Design, Research and Development (RDCONF) 2021 - 15-18 December 2021)

(DOI: 10.31590/ejosat.1039397)

ATIF/REFERENCE: Gülekçi, Y. (2021). Effects of Environmental Factors on Fingerprint DevelopmentEuropean Journal of Science and Technology, (32), 463-470.

\begin{abstract}
Fingerprints are unique to individuals and play an important role in the investigations at the crime scene. Today searches for developing the best methods to detect the fingerprints that are not completely visible or not have sufficient characteristics are still ongoing. In this study, 2448 fingerprints were used as samples collected from four individuals, between 24-50 years old, two women and two men, who signed the consent form as material. Porous and nonporous materials were used to develop fingerprints in the laboratory. Glass, metal, and plastic materials were used as nonporous materials. Cyanoacrylate vapor and staining methods were used for non-porous materials. Iodine vapor, ninhydrin, and silver nitrate were used for porous materials such as paper and raw wood. Image sharpening was performed by taking high-quality photographs for each sample. Thus, fingerprints were identified. Fingerprints that can and cannot be classified were successfully compared and their data were calculated. The experimental results showed that surface types are extremely important in the elucidation of the event in detecting hidden fingerprints of the perpetrator.
\end{abstract}

Keywords: Crime Scene Investigation, Fingerprint, Environmental Conditions, Fingerprint Development Methods

\section{Çevresel Faktörlerin Parmak İzi Gelişimine Etkileri}

\section{$\ddot{\mathbf{O} z}$}

Parmak izleri kişilere özeldir ve olay yeri incelemelerinde önemli bir rol oynar. Günümüzde tam olarak görülemeyen veya yeterli özelliklere sahip olmayan parmak izlerinin tespit edilmesi için en iyi yöntemlerin geliştirilmesi arayışları devam etmektedir. Bu çalışmada, materyal olarak onam formunu imzalayan 24-50 yaş arası, iki kadın ve iki erkek olmak üzere dört kişiden örnek olarak 2448 parmak izi kullanılmıştır. Laboratuvarda parmak izi geliştirmek için gözenekli ve gözeneksiz malzemeler kullanıldı. Gözeneksiz malzeme olarak cam, metal ve plastik malzemeler kullanılmıştır. Gözeneksiz malzemeler için siyanoakrilat buharı ve boyama yöntemleri kullanıldı. Kağıt ve ham ahşap gibi gözenekli malzemeler için iyot buharı, ninhidrin ve gümüş nitrat kullanılmıştır. Her numune için yüksek kaliteli fotoğraflar çekilerek görüntü netleştirme yapılmıştır. Böylece parmak izleri tespit edilmiş oldu. Sınıflandırılabilen ve sınıflandırılamayan parmak izleri başarılı bir şekilde karşılaştırılmış ve verileri hesaplanmıştır. Deneysel sonuçlar, failin gizli parmak izlerinin tespit edilmesinde olayın aydınlatılmasında yüzey tiplerinin son derece önemli olduğunu göstermiştir.

Anahtar Kelimeler: Olay Yeri İnceleme, Parmak İzi, Çevre Koşulları, Parmak İzi Geliştirme Yöntemleri

\footnotetext{
* Sorumlu Yazar: yakup.gulekci@ksbu.edu.tr
} 


\section{Introduction}

Crime scene investigation procedures have a very important role in the judicial system to establish a link between the perpetrator and the victim. Collecting legal evidence, conducting necessary criminal investigations and analyzes is crucial to ensuring justice, and this is only possible with a healthy and informed crime scene investigation (Britain (1988); Bowman (2009)).

One of the important purposes of crime scene investigation is fingerprint detection, which will be used for perpetrator detection. The fingerprint formed from the moment a person was born and the patterns formed by the papillary lines remain in their way. Fingerprints that are unique to individuals are differently characterized on all fingers (Barnum and Klasey (1997)). Fingerprints, which are shown as a good reference in personal identification due to the complex structure, stability, and uniqueness of the papil lines, still play an important role in criminal investigations and judicial proceedings. The moist layer formed on papillary lines containing numerous sweat pores can be transferred to the surface of the touched object. However, there may be fingerprints that do not appear on the scene, without sufficient characteristic dots. The methods to obtain this evidence in the most efficient way are still being investigated (Neumann (2012)).

There are three types of fingerprints on the crime scene: visible fingerprints (oily, painted, bloody, etc.), relief fingerprints (paste, soap, candles, etc.) and invisible fingerprints (latent). Invisible (latent) fingerprints are the most commonly tried to be detected. To detect fingerprints efficiently, the type of surface and the environment where the material is located must be accurately defined. Surfaces are classified as porous and nonporous. The fact that the material surfaces are different in terms of fingerprint examination (porous-nonporous surface) ensures that they are different in the methods used. In determining the most suitable method to be used, the condition of the surface, its structure (rough-smooth, absorbent-non-absorbent, etc.), the presence of residues affecting the fingerprint (oil, blood, etc.), the duration of the fingerprint on the surface and environmental factors (wetting, drying, etc.) are taken into account (Neumann (2012); Ramotowski (2012)).

On the porous surfaces that are absorbent and absorbable, such as paper and its derivatives, raw wood, among the fingerprint development methods; 1odine vapor, ninhydrin, DFO (9-Diazaflueron), indanedione, 5-MTN (5- (methylthio) ninhydrin), thermanin, silver nitrate, and zinc chloride are used. non-absorbent nonporous surfaces such as metal, glass, plastic, nylon, fluorescent paints such as cyanoacrylate, Rhodamine-6G, Ardrox, Nile Red, Yellow Basic, Sudan Black, Gention Violent, Sticky Side, Amido Black, Hungarian Red, SPR chemicals are used. Nonporous surfaces are highly affected by external factors due to not exhibiting absorbency and absorbability (Gardner and Krouskup (2018)).

For such proofs, methods are developed that can obtain the most suitable and best view from the surface on which the trace is left (Upadhyay and Yadav (2019)).
They claimed that ninhydrin could be used by Oden and von Hofsten to heal hidden fingerprints. It has since been used as the most common reagent used to make fingerprints visible on porous surfaces. Ninhydrin, a powerful organic oxidant, reacts with fingerprint amines, the amino acid residue. Low-cost and easy-to-manufacture ninhydrin also provides high resolution by giving strong colors as a result of the reaction.

Another effective parameter in using the ninhydrin method, as an important approach for porous materials, is the environment in which the evidence exists. If the material is wet for invisible fingerprints, the iodine vapor method is used. Iodine vapor, which is a physical developer with water-soluble components, is an effective method in criminal investigations, especially when used appropriately and safely (Gardner and Krouskup (2018); Daluz (2018)).

Fingerprints that develop with iodine vapor produce brown prints, and rapid fading is observed in contrast-aware so it should be photographed shortly after being fixed on a nonporous surface.

Cyanoacrylate substance, which selectively polymerizes the fingerprint forming papillary lines, producing a white-colored polymeric structure is used to determine the latent fingerprint in some methods.

Evidence collected from the crime scene is based on placing the cyanoacrylate substance in a cabinet and heating it with steam and exposing the evidence to steam. After the traces are developed, dying is performed to create a contract. (Daluz (2018); Hazen (1980)).

In this study, the effects of fingerprints left on porous and non-porous surfaces with the help of volunteers were investigated according to various factors including age, gender, time, temperature, humidity, fresh-salt water, and pressure effects in the laboratory environment. 2448 fingerprint samples were left on various surfaces.

Cyanoacrylate vapor and dyeing methods were used on nonporous surfaces such as glass, metal, plastic, and nylon. The ninhydrin method was applied to the paper in the air environment. Ninhydrin and silver nitrate (AgNO3) methods were applied to the raw wood surfaces.

Iodine vapor was applied to the materials removed from the fresh-salt water environment. Fingerprints that can and cannot be classified according to the variables affecting the fingerprint were determined in all periods of the study. Hitherto, the effects of the different surfaces on the fingerprints have not been investigated (Ramotowski (2012)). In this paper for the first time, the effects of surface types and environmental conditions on fingerprint detection were investigated. Also, the factors affecting the surface types and ambient conditions were determined in the study to provide forecasts. Thus, the works of the scene specialists are facilitated. 


\section{Material and Method}

\subsection{Collection and Preparation of Fingerprint Samples}

All protocols are carried out in accordance with relevant guidelines and regulations, a statement confirming all the methods are approved by Kutahya University of Health Sciences the institutional Ethical Committee the informed consent was obtained from all participants for the study. Consent to the publication of identifying information/images in an online openaccess publication was obtained from all the participants in informed consent forms.

In the study, the fingerprint samples of four people, two women and 24-50 years old, who signed the consent form, were used as materials. Two young people and two middle-aged individuals were selected to investigate personal factors that affect the development of fingerprints. Fingerprint samples were taken from donors for each condition (ambient conditions, temperature, humidity, etc.) affecting fingerprint development. Volunteers did not wash their hands for 20 minutes before leaving a fingerprint sample on the surfaces. Fingerprint samples were created from samples that are frequently encountered at the crime scene.

Fingerprints; The microscope slide for glass surfaces, A4 paper for paper surfaces, lath for raw wooden surfaces, galvanized sheet metal parts for metal surfaces, mica for plastic surfaces, and transparent vegetable bag for nylon surfaces were placed at 2-minute intervals. Care was taken to ensure that the contact times did not exceed 10 seconds. Personal information was labeled so that fingerprints were not mixed or to prevent contamination.

\subsection{Methods used for fingerprint development}

Four different methods were used to improve fingerprints on porous and nonporous surfaces in air and water environments. Cyanoacrylate vapor and fluorescent dyeing methods were used for metal, glass, plastic, and nylon materials. Iodine vapor method was applied to paper and raw wood surface materials extracted from the water environment. The contrast difference was clarified by applying the ninhydrin method on paper surfaces evaluated in the air environment and ten days later by applying the ninhydrin method the silver nitrate $\left(\mathrm{AgNO}_{3}\right)$ method was applied on the raw wood for clarifying.

Cyanoacrylate steam method; non-porous surfaces (metal, glass, plastic, etc.) fingerprint enhancement were placed in a cabinet with a volume of $0.5 \mathrm{~m}^{3}$ (Sircihe, USA) in a way not to touch each other. Cyanoacrylate (Evobond 502 Super Glue), a single-component, solvent-free adhesive that will spread homogeneously to the interior volume of the application, drying quickly for 2 to 50 seconds, has high heat resistance, provides a small adhesion. penetrates even very small areas. It was placed in a container of about 40 drops and left on the heating table. The temperature of the heating table in the application cabinet was adjusted to $120{ }^{\circ} \mathrm{C}$. For the development of fingerprints, the humidity level of the environment was $80 \%$ moistened and the humidity level was controlled. For the development of fingerprints, the findings were kept on average for cyanoacrylate vapor for 15-20 minutes.
The chain reaction that took place enabled the lines on the fingerprints to form, making the fingerprint visible. The fingerprints developed visibly and in white. After the development of the fingerprints was completed, the poisonous gas inside the cabin was evacuated and the environment was ventilated.

If there were visible fingerprints, photographing was taken immediately. If fingerprints developed poorly, cyanoacrylate vapor was applied to the surfaces again. The most common fluorescence dyeing methods such as Ardrox and Rhodamine 6G used it to clarify the weak fingerprint image created by the cyanoacrylate steaming method. The developing fingerprints were photographed. 0.1g Rhodamine 6G (Merck, Germany) was weighed and the stock solution was prepared by dissolving in $100 \mathrm{~mL}$ of methanol. $3 \mathrm{~mL}$ of prepared stock solution, $15 \mathrm{~mL}$ of acetone (Merck, Germany), $10 \mathrm{~mL}$ of acetonitrile (Merck, Germany), $15 \mathrm{~mL}$ of methanol (Merck, Germany), $32 \mathrm{~mL}$ of propanol (Merck, Germany), $925 \mathrm{~mL}$ of petroleum ether (Merck, Germany), $1000 \mathrm{~mL}$ working solution was prepared. Rhodamine 6G; Cyanoacrylate application materials were brought into contact with the entire surface. The evidence surface was washed with running water without pressure. The evidence was kept in a vertical position in a suitable environment and the surface was allowed to dry. Traces developed with Cyanoacrylate vapor and dyed fluorescently with Rhodamine $6 \mathrm{G}$ method were seen when the Lumatec Superlite S400 model was applied with wavelength lights between $470 \mathrm{~nm}$ and $530 \mathrm{~nm}$ with a multi-wavelength light source. Maximum absorption was achieved by an orange filter under $515 \mathrm{~nm}$ wavelength light. The developing fingerprints were photographed.

For the preparation of Ardrox working solution, $2 \mathrm{~mL}$ of Ardrox (Sircihe, USA), $10 \mathrm{~mL}$ of acetone (Merck, Germany), 25 $\mathrm{mL}$ of methanol (Merck, Germany), $10 \mathrm{~mL}$ of propanol (Merck, Germany), $8 \mathrm{~mL}$ of acetonitrile (Merck, Germany), $1000 \mathrm{~mL}$ working solution was prepared using $945 \mathrm{~mL}$ petroleum ether (Merck, Germany). The prepared working solution was brought into contact with the entire surface of the cyanoacrylate applied materials. The materials were washed with running water without pressure. The materials were kept in a vertical position in a suitable environment and the surface was dried. Traces developed with Cyanoacrylate vapor and painted fluorescently with Ardrox method were observed when Lumatec Superlite S400 model was applied with wavelength lights between $415 \mathrm{~nm}$ and $470 \mathrm{~nm}$ with a multi-wavelength light source. Maximum absorption was achieved with a yellow filter under $415 \mathrm{~nm}$ wavelength light. The developing fingerprints were photographed.

Iodine Vapor, paper, and raw wood materials removed from the water environment were placed so that they do not touch each other in the fingerprint development cabinet. For the application of iodine vapor, $2 \mathrm{~g}$ of iodine (Sirchie, USA) were weighed. Iodine was placed in the glass container on the heater inside the fingerprint development cabinet. The temperature of the heating table was set at $90{ }^{\circ} \mathrm{C}$. It was observed that iodine crystals evaporated to form a pinkish vapor. After sufficient contrast difference was observed between the fingerprints and the material surface, the cabin was put into ventilation. The fingerprints formed developed visibly and in brown. After the development of the fingerprints was completed, the poisonous gas inside the cabin was evacuated and the environment was ventilated. Photographing was done immediately for fingerprints that became visible. 
Ninhydrin (Sirchie, USA) weighed $4 \mathrm{~g}$ and the solution was prepared by dissolving $20 \mathrm{~mL}$ of methanol (Merck, Germany). $1000 \mathrm{~mL}$ of working solution was prepared by adding $70 \mathrm{~mL}$ of ethyl acetate (Merck, Germany), $10 \mathrm{~mL}$ of acetic acid (Merck, Germany), and $900 \mathrm{~mL}$ of petroleum ether (Merck, Germany) onto the stock solution. Porous surfaces were immersed in a prepared ninhydrin solution for 10 seconds and the materials were left to dry for 3 minutes. It was kept for an average of 10 days in a dark environment for the scars to develop. The fingerprints formed developed visibly and in purple. The developing traces were photographed.

For the Silver Nitrate method, $10 \mathrm{~g}$ of silver nitrate (Sirchie, USA) was weighed and dissolved in $500 \mathrm{~mL}$ of methanol (Merck, Germany), and the working solution was prepared. It is immersed in silver nitrate solution for 5 seconds for quality development of fingerprints on raw wood surfaces. It was left to dry completely in a dark environment. Lumatec Superlitte S400 model, high-luminous white light emitted from the multiwavelength light source was applied until it began to darken to the raw wooden surface. The fingerprints formed developed visibly and in dark brown color. It was kept in the dark until photographing. The developing traces were photographed.

Fingerprint samples were analyzed to see if they were suitable for identification by applying the highest quality photographs (Nikon D7200 Camera - Sigma 105mm F / 2.8 EX DG OS HSM Macro Lens) and image sharpening (AdobePhotoshop CS6).

\subsection{Relationship between Fingerprint and Environmental Conditions}

Fingerprints taken from volunteers are provided on the different surface types, and environments that can be encountered at the scene are provided, and seven fingerprints were developed in different periods of $1^{\text {st }}$ day, $1^{\text {st }}$ week, $1^{\text {st }}$ month, $3^{\text {rd }}$ month, $6^{\text {th }}$ month, $9^{\text {th }}$ month and $12^{\text {th }}$ month in both air and water environments.

Fingerprint samples were placed in cages of $20 \times 5 \times 20 \mathrm{~cm}$ placed in the Marmara sea, Istanbul for the saltwater environment. Fingerprints were placed in the $65 \times 45 \times 25 \mathrm{~cm}$ sized aquarium of lake waters taken from Büyükçekmece lake for freshwater. In total, 504 fingerprint samples were used. The sample surfaces removed from the water environment were passed through low flowing water in each trial period, and the formation of deposits on the sample surfaces that would adversely affect fingerprint development was prevented. Thus, it was determined how long the fingerprints would be suitable for identification under which environmental conditions at the scene.

\subsection{Fingerprint and Temperature Relationship}

Fingerprint samples; Five attempts were performed in threemonth periods $\left(0\right.$.month, $3^{\text {rd }}$ month, $6^{\text {th }}$ month, $9^{\text {th }}$ month, and $12^{\text {th }}$ month), provided that they were exposed to $50^{\circ} \mathrm{C}, 90^{\circ} \mathrm{C}$, $110^{\circ} \mathrm{C}, 150^{\circ} \mathrm{C}, 200^{\circ} \mathrm{C}, 300^{\circ} \mathrm{C}$ degrees for three minutes for each degree. The fingerprints of the people were left on 6 different surfaces, at 6 different temperatures, in 5 different periods and a total of 720 samples were used.

\subsection{Fingerprint and Moisture Relationship}

Fingerprint samples; In $60 \%, 80 \%$, and $100 \%$ humid environments, three trials were performed in 3 different time intervals $\left(1^{\text {st }}\right.$ hour, $2^{\text {nd }}$ hours, and $3^{\text {rd }}$ hours $)$ for six months $(0$. e-ISSN: 2148-2683 month, $6^{\text {th }}$ month and $12^{\text {th }}$ month). Individuals have left their fingerprints on 6 different surfaces, at 3 different humidity, in 3 different time intervals, and a total of 648 samples were used.

\subsection{Fingerprint and Pressure Relationship}

Fingerprint samples; The amount of force acting on the unit area was increased by using $400 \mathrm{~g}, 600 \mathrm{~g}$, and $800 \mathrm{~g}$ weights on the finger, and three attempts were made in six-month periods (0. month, $6^{\text {th }}$ month and $12^{\text {th }}$ month). The amount of 3 different forces acting perpendicular to the surface, leaving the fingerprints of the individuals on 6 different surfaces, provided that the surface area remains constant, was left in 3 different time intervals and a total of 216 samples were used.

\section{Results and Discussion}

\subsection{Results}

The results of the fingerprint samples were classified according to whether they are suitable for identification by checking at least 13 fingerprint features (Figure1).
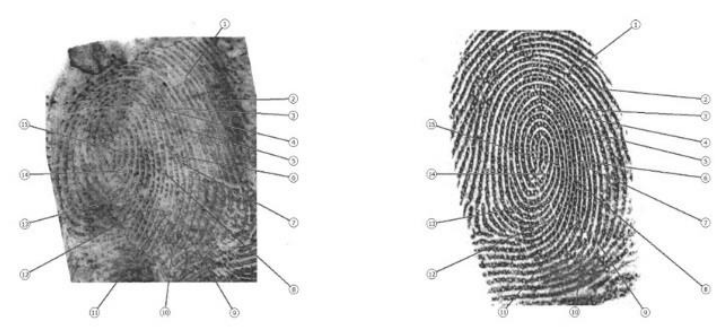

Figure 1. Analyzing whether the detected Fingerprint is suitable for identification.

Analyzing whether the detected Fingerprint is suitable for identification.

As fingerprints were analyzed under environmental conditions, it was determined 18 glass, 20 metal, 15 plastic, 12 nylon, 8 paper, and 4 wooden surfaces suitable fingerprint numbers for identification in the freshwater environment.

Also, it was determined 16 glass, 20 metal, for plastic, 10 nylon, 1 paper suitable fingerprint number for identification in the saltwater environment, and fingerprint development on wooden surfaces could not be detected.

On the other hand, fingerprints left in the air environment were found to be relatively more classifiable in terms of surface types compared to fresh and saltwater environments. It was determined that the number of suitable fingerprints for identification in the air environment was 26 glass, 26 metal, 25 plastic, 24 nylon, 25 paper, and 20 wooden surfaces (Figure2). 


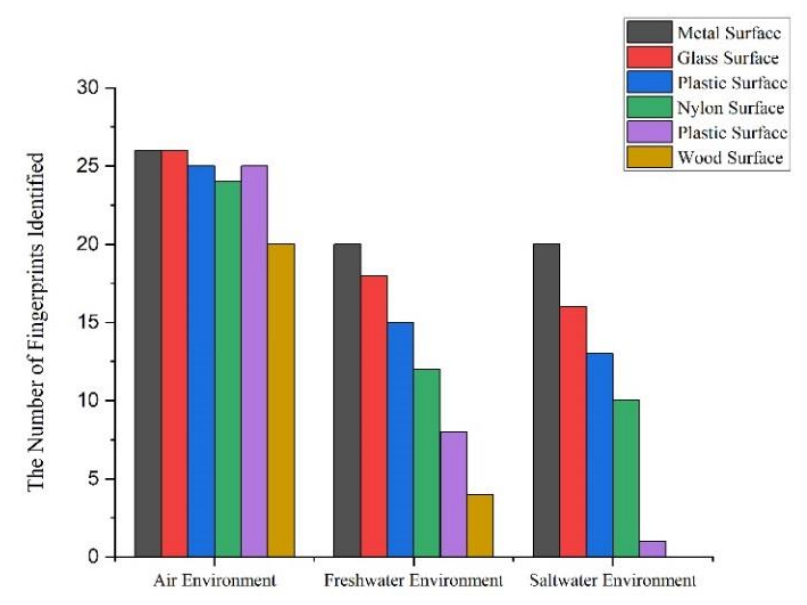

Figure 2. Comparison of the number of fingerprints according to surface types.

It was determined that the most suitable surface for fingerprint development in air and salt-freshwater environments were glass and metal surfaces. (Figure 3)
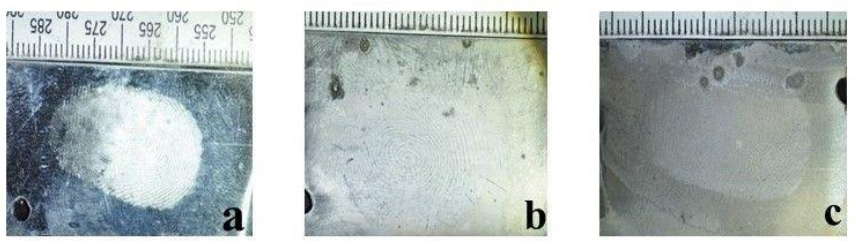

Figure 3. Fingerprint Development on Metal Surfaces; a) 12 months trace development in the air environment, b) 90 days trace development in the freshwater environment, c) 30 days trace development in the saltwater environment

While fingerprints were classified for 90 days in the freshwater environment and 30 days in the saltwater environment, the development of fingerprints suitable for identification up to 12 months in an air environment was provided. Fingerprint detection suitable for identification from paper and raw wood surfaces was obtained in the 1st day and 1st-week trials. It was observed that the porous surfaces were dispersed and the raw wooden surfaces swelled after the 4 weeks in the water environment. However, the number of fingerprints suitable for the identification of all surface types in the air environment decreased during the 12-month working period. (Figure 4)

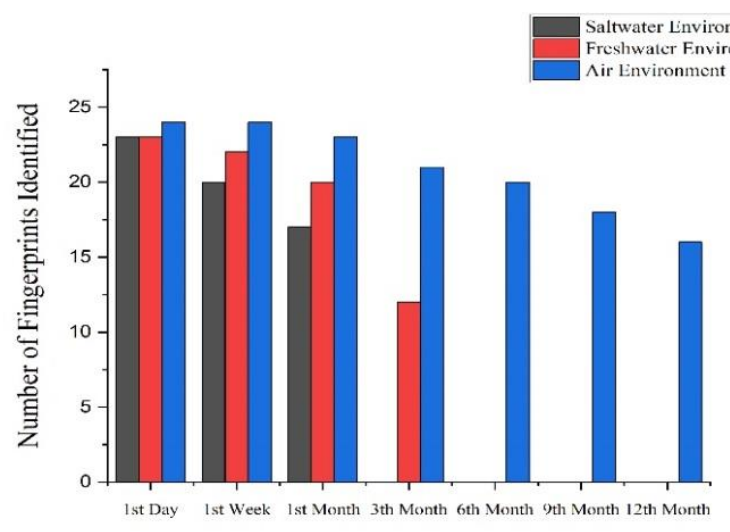

Figure 4. Evaluation of the number of fingerprints suitable for identification obtained from all surfaces over time.
When fingerprint samples taken from donors were evaluated in terms of personal factors (age, gender, etc.), air and water environments showed characteristic similarities. In this context, when compared to the air environment, 79 fingerprints of men and 67 of women were observed. When the suitable number of fingerprints for identification of young and old individuals is compared, 82 fingerprints of young individuals between the ages of 24-30 and 64 people aged between the ages of 45-50 have been identified.

When the effects of temperature change on fingerprint development were evaluated, although the number of fingerprints suitable for identification decreased as the temperature increased, fingerprints suitable for identification up to $300{ }^{\circ} \mathrm{C}$ were obtained. (Figure 5)

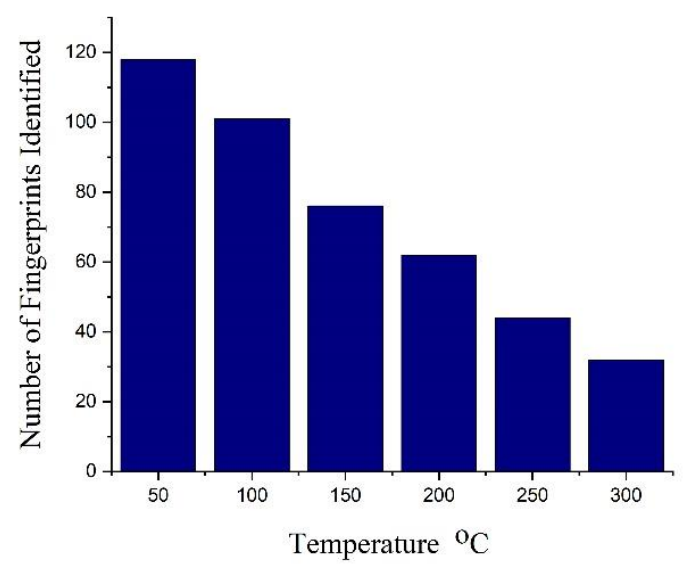

Figure 5. Number of fingerprints identified versus the temperature increase

At all temperature values; 118 fingerprints on glass surfaces, 112 on metal surfaces, 62 on plastic surfaces, 52 on nylon surfaces, 102 on paper surfaces and 86 on wooden surfaces were determined. Fingerprints were not detected since melting occurred in $200{ }^{\circ} \mathrm{C}$ and $300{ }^{\circ} \mathrm{C}$ plastic and nylon materials.

It was observed that the material was the glass surface in the temperature parameter that can be classified most efficiently until the $9^{\text {th }}$ month. Figure 6 . as can be seen, the fingerprints developing at all temperatures in the $9^{\text {th }}$ month were photographed after fixation.
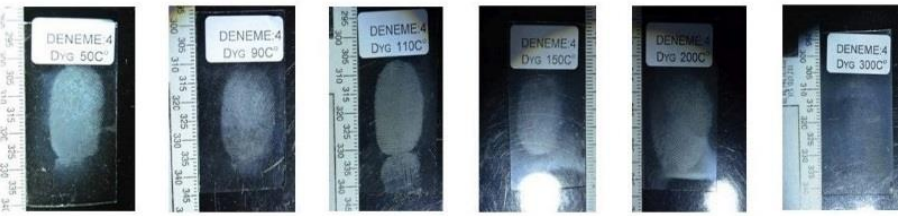

Figure 6. Fingerprint development suitable for identification according to temperature changes on glass surfaces

Ardrox and Rhodamine 6G fluorescence dyeing methods were applied after applying the cyanoacrylate steam method to glass surfaces in which fingerprints can be classified most efficiently for up to 90 days in the freshwater environment and 30 days in the saltwater environment. As shown in Figure 7, the maximum absorption with the Ardrox method was achieved with a yellow filter under the wavelength of $415 \mathrm{~nm}$. In the Rhodamine $6 \mathrm{G}$ fluorescence method, maximum absorption was achieved by an orange filter under $515 \mathrm{~nm}$ wavelength light. 

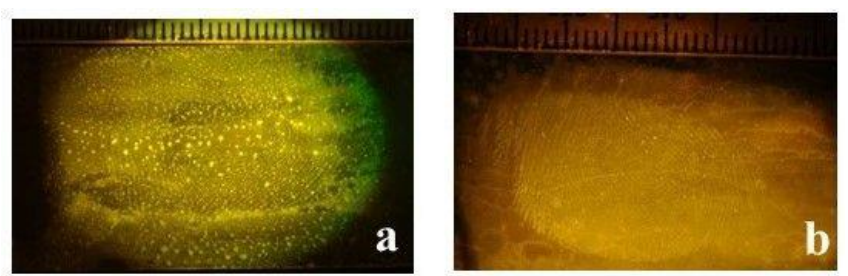

Figure 7. Ardrox and Rhodamine 6G fluorescent painting methods applied to glass surfaces

When it was analyzed in terms of the relationship between detectable fingerprints, it was determined that there were 199 fingerprints at $60 \%$ humidity, 210 at $80 \%$ humidity, and 204 at $100 \%$ humidity (Figure 8).

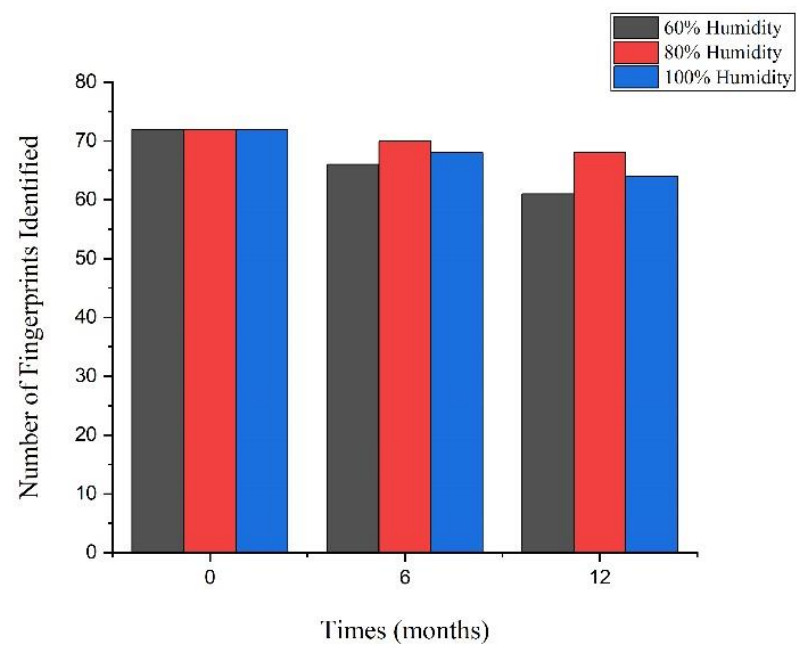

Figure 8. Evaluation of fingerprints according to humidity and time

As shown in Figure 9. 60\%, 80\%, and 100\% humidity tests were evaluated by photographing after fingerprints developed and it was found that the optimum humidity rate was $80 \%$.
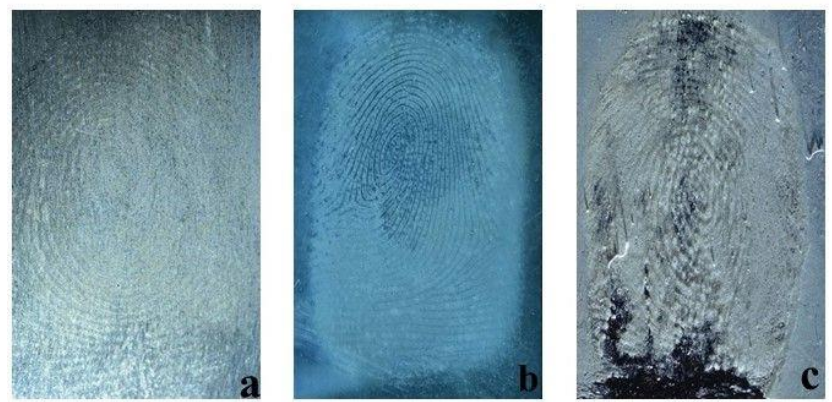

Figure 9. Fingerprints developed in moisture a) $60 \%$, b) $80 \%$, c) $100 \%$

We compare fingerprint development in terms of the amount of force (pressure) applied to the surface; While the fingerprint samples were transferred to the surface, the amount of force applied to the unit surface was determined as 65 for $400 \mathrm{~g}, 40$ for $600 \mathrm{~g}$, and 15 for $800 \mathrm{~g}$ fingerprints (Figure 10)

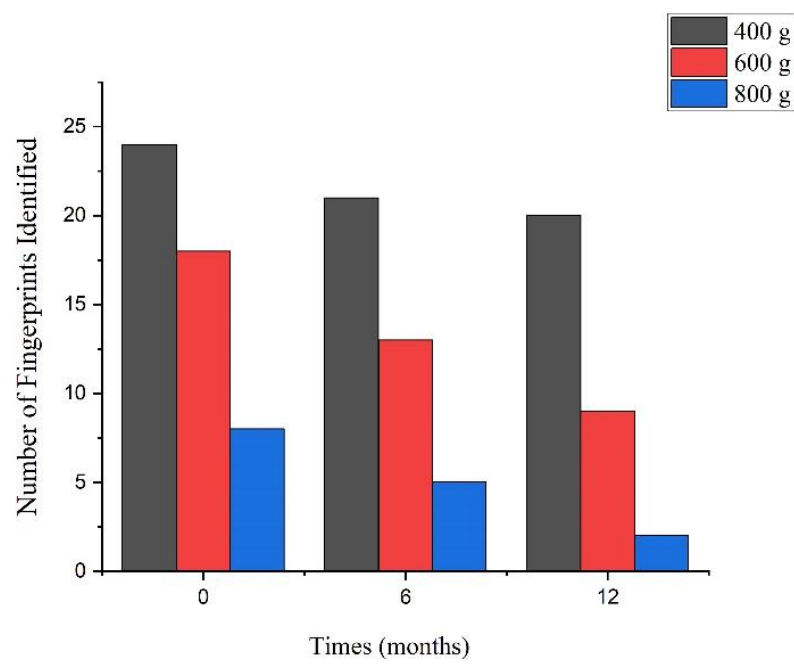

Figure 10. Evaluation of the time relationship between the amount of force applied to the unit surface and fingerprints

\subsection{Discussion}

Each method used in the study finds application in different situations and within certain standards. To determine the most convenient method, some factors such as condition and structure of the surface (rough-smooth, absorbent-non-absorbent, etc.), whether any residues are affecting the fingerprint (oil, blood, etc.), environmental factors (wetting, drying, etc.), possible age of the fingerprint (stay on the surface time) were taken into account (Neumann (2012)).

In the criminal investigations, the process in which the evidence was first detected from the scene and examined by criminal laboratories; The effect of temperature, the development of fingerprints in the air and water environment the quality of the materials evaluated as evidence at the scene, and how much identification was determined. The evaluations on the detected analyses revealed that various factors like humidity effects, personal factors were found to be effective on the fingerprinting age. Fingerprints on surfaces are more classifiable than in freshwater saltwater. This is an expected result because the pressure applied on the surface varies with the water flow, the pollution of the water, the chemicals in the water, the $\mathrm{pH}$, the bottom surface of the water, the living things in the water (Gardner and Krouskup (2018); Bleay et al. (2018)). The fingerprints are suitable for identification in water environments varies depending on the duration of stay. Because it is known that substances other than oils in fingerprint liquid, such as amino acids, dissolve in the water environment. This situation led to the development of fingerprints on various surfaces at different time intervals, although the fingerprint development methods used in the study were stable. Also, wet materials should be removed from the environment in a short time and they should be examined by making cleaning processes for water environments (Amata et al. (2015)).

The fingerprint development of porous materials such as paper and raw wood suitable for identification in water environments has been determined in the laboratory environment in the 1 st day and 1 st-week trials. Porous surfaces used lost their quality of evidence within 4 weeks. In a study, it is reported that the fingerprints are taken freshly improved better than the old fingerprints as well as the age of the perpetrator (Gardner and Krouskup (2018)). For these reasons, it has been observed that 
fingerprints on nonporous surfaces such as glass and metal used in the water environment compared to materials such as paper and raw wood are more permanent and more efficient and fingerprints are classifiable.

In this study, it was observed that nonporous materials extracted from fresh and saltwater environments were classified by the cyanoacrylate steam method and dyeing method for 90 days in the freshwater environment and 30 days in the saltwater environment.

Fingerprints left in the air environment have relatively more classifiable results compared to the freshwater and saltwater environments. Considering the air environment and other variables, it has been determined that fingerprints may be evidence for a longer period, especially as porous surfaces such as paper trap the secretions that make up the fingerprint (Schwarz and Hermanowski (2012)). Despite many variables in the air environment, fingerprints on the surfaces; It is possible to detect fingerprints suitable for identification for more than 12 months unless exposed to physical friction in room conditions.

When temperature values and fingerprints are evaluated, it is determined that suitable fingerprints up to $300{ }^{\circ} \mathrm{C}$ can be detected, but fingerprints suitable for identification at $50{ }^{\circ} \mathrm{C}$ are more favorable than other temperatures. The oil layer forming the fingerprint up to $300{ }^{\circ} \mathrm{C}$ shows durability. It has been determined that fingerprints left on metal and glass surfaces at all temperature values are more suitable for identification than plastic, nylon, paper, and wooden surfaces. The extent to which fingerprints affect the development of the marks in the cases of fire and swaddling of the fingerprints left on the non-porous surfaces and the development of the fingerprints on the surfaces in the center of or around the burn has not been detected.

In the study, as the waiting time (fingerprint age) on the surfaces of the fingerprints increases, the amount of moisture used in making the fingerprint visible is increased. However, when the fingerprint age increases, in $60 \%$ of the humidity, fingerprint development is adversely affected, while the papillary gaps in the fingerprints are filled in the time interval when the humidity is $100 \%$. The ideal humidity rate for fingerprint development was determined to be $80 \%$.

In fingerprint research; The increase in temperature and humidity in the environment also increases the temperature of the surfaces where fingerprints are placed. This situation causes the evaporation of water and some molecules in the fingerprints placed on the surface. Therefore, fingerprint development is affected negatively in hot and humid weather.

When we compare fingerprint quality according to humidity and time factor, it is determined that there is a high number of fingerprints suitable for identification in all moisture rates in the first attempt, and humidity is not a distinctive factor on fresh fingerprints. As the fingerprint age increases, the need for moisture increases and becomes a determining factor in fingerprint development.

When the fingerprints are transferred to the surface, as the force applied on the unit surface increases, a significant decrease in the number of fingerprints suitable for identification was detected. The main reason for this situation is that the secretions from the por holes that make up the fingerprint are transferred to the surface within a maximum of 10 seconds and the natural appearance of the fingerprint deteriorates as the pressure force increases unintentionally as the time progresses. In the literature, it has been proven that the number of epithelial cells left by the first contact and the secretions emerging from the por holes does not increase the secretion and the number of cells during the contact times of over 10 seconds (Balogh et al. (2003); Deans (2006)). Therefore, in this study, the amount of secretion coming from the por holes was distributed equally to each surface by waiting for 2 minutes between the surfaces. Care was also taken to ensure that the contact times did not exceed 10 seconds.

Also, it is known that it plays an important role in personal factors such as age, gender, etc. in determining the permanence and quality of fingerprints (Trapecar (2007))

When the number of fingerprints of women and men who participated in the experiments during the study was compared, it was found that fingerprints taken from men were more suitable for identification. Since the amount of fluid secreted by women per unit time is less than that of men, they leave less fingerprint liquid on the surface they touch. This causes the latent fingerprint quality to be lower (Gardner and Krouskup (2018); Khadri et al. (2013)).

When comparing the number of fingerprints suitable for identification of young and old individuals participating in the experiments during the study, it was found that the number of fingerprints suitable for identification of young individuals (2430 years old) was very high compared to older individuals (4550 years old). The number of sebacus and ecrin glands, which have an important place in the formation of fingerprints, decreases with age. Therefore, an increase in the number of fingerprint fluids caused by factors such as instant emotional changes is observed. Also, because of the reduction in the number of amino acids and fats in fingerprints of older people, young people can't develop fingerprints of the quality, in which the quality of young people improves their fingerprints (Ramotowski (2012); Daluz (2018)).

\section{Conclusions}

In the crime scene investigation practices, we think that the work we do about the fingerprint investigation will facilitate the identification of the fingerprints of the perpetrator and that the crime scene investigators will gain insight into the evaluation of the surface types in the fingerprint examinations. Also, we believe that the fingerprints of the offender from the evidence obtained at the crime scene will be the pioneer for the fingerprints, which are the most important evidence in determining the identity of the perpetrator by applying different fingerprint development methods along with the conditions affecting the fingerprint development, and performing these procedures in laboratory conditions.

\section{References}

Britain, G. (1988). Manual of fingerprint development techniques: a guide to the selection and use of processes for the development of latent fingerprints. Home Office, Scientific Research and Development Branch.

Bowman, V. (2009). Manual of Fingerprint Development Techniques, 3rd rev. Home Office, Police Scientific Development Branch: Sandridge, UK.

Barnum, C., \& Klasey, D. (1997). Factors affecting the recovery of latent prints on firearms. Journal of Forensic Identification, 47, 141-149. 
Neumann, C. (2012). Fingerprints at the crime-scene: Statistically certain, or probable?. Significance, 9(1), 21-25.

Ramotowski, R. (Ed.). (2012). Lee and Gaensslen's advances in fingerprint technology. CRC press.

Gardner, R. M., \& Krouskup, D. (2018). Practical crime scene processing and investigation. CRC Press.

Upadhyay, S., \& Yadav, B. (2019). Latent Fingerprint on Human Skin: A Silent Diagnosis. J Forensic Sci Criminol, 7(2), 205.

Daluz, H. M. (2018). Fingerprint analysis laboratory workbook. CRC Press.

Hazen, R. J. (1980). A Review of Scott's Fingerprint Mechanics. Journal of Forensic Science, 25(2), 450-450.

Bleay, S. M., Croxton, R. S., \& De Puit, M. (2018). Fingerprint development techniques: theory and application.

Amata, B., Aprea, G. M., Chiuri, A., \& Zampa, F. (2015). Fingerprint on trigger: a real case. Forensic science international, 253, e25-e27.

Schwarz, L., \& Hermanowski, M. L. (2012). The Effect of Humidity on Long-Term Storage of Evidence Prior to Using Cyanoacrylate Fuming for the Detection of Latent Fingerprints. Journal of Forensic Identification, 62(3).

Deans, J. (2006). Recovery of fingerprints from fire scenes and associated evidence. Science \& justice: journal of the Forensic Science Society, 46(3), 153-168.

Balogh, M. K., Burger, J., Bender, K., Schneider, P. M., \& Alt, K. W. (2003). STR genotyping and mtDNA sequencing of latent fingerprint on paper. Forensic science international, 137(2-3), 188-195.

Trapecar, M., \& Balazic, J. (2007). Fingerprint recovery from human skin surfaces. Science \& Justice, 47(3), 136-140.

Khadri, S. Y., Goudar, E. S., \& Khadri, S. Y. (2013). A study of fingerprint pattern and gender distribution of fingerprint in and around Bijapur. Al Ameen J Med Sci, 6(4), 328-331.

\section{Ethical Statement}

The author confirms that all experiments were conducted in accordance with the relevant guidelines and regulations. The author confirms that all methods were carried out in accordance with the relevant guidelines and regulations. The author confirms that the informed consent was obtained from all subjects or, if the subject is under 18, from a parent and / or legal guardian. Approval was obtained from all participants in the informed consent forms to publish identifying information / images in an online open access publication. 